\title{
Heart rhythm during permanent cardiac pacing
}

\author{
OLOF EDHAG AND MARTEN ROSENQVIST \\ From the Department of Medicine, Serafimerlasarettet, Stockholm, Sweden
}

SUMMARY Heart rhythm was analysed with regard to spontaneous or pacemaker-induced heart activity, in a consecutive series of 282 patients paced for at least 1 year. The mean duration of pacing was 59 (13 to 180) months. The mean age of the patients was 76 (39 to 93) years. Spontaneous heart activity at all routine examinations was found in $33(12 \%)$ of the patients. Pacemaker-induced rhythm only was recorded in 42 per cent of the patients whereas the remaining 46 per cent had varying electrocardiographic patterns. Of the patients with spontaneous rhythm at each visit, 10 had had complete heart block before pacing. Regular sinus activity was recorded at every routine examination in 74 per cent of the patients paced for reasons other than the sick sinus syndrome. This indicated that a substantial number of paced patients might be candidates for atrial triggered pacing. Patients treated with digitalis more often had asystole at the time of replacement of the pacemaker $(32 \%)$ than those not so treated $(19 \%)$. This suggests an increased risk of sudden death in paced patients on digitalis if the pacemaker fails.

Patients who require permanent cardiac pacing are generally considered to need this treatment for the rest of their lives. Several reports have, however, appeared showing that symptomatic high degree atrioventricular block sometimes is transient (Johansson et al., 1963; Sowton, 1965; Donato et al., 1969; Jensen et al., 1973). Furthermore, longterm follow-up shows a substantial proportion of paced patients with spontaneous heart activity faster than the basic rate of the pulse generator. These observations led us to analyse the heart rhythm of a consecutive series of patients who required cardiac pacemakers because of various symptomatic bradyarrhythmias.

\section{Subjects and methods}

We included patients who had had cardiac pacemakers for at least 1 year and who were regularly followed-up at the Medical Department of Serafimerlasarettet, Stockholm. We excluded those who were paced because of tachyarrhythmias, those with atrial triggered pulse generators, and those who, during the collection of data, had moved from the region. There were 282 patients, 121 were women and 161 were men. The mean age was 76 years (range 39 to 93). Three patients were less than 50 years, 72 patients were between 51 and 70 years, and 207 patients were over 70 years. Pacemaker function was tested with electrocardiographic recordings 3 to 5 times a year. Seventy-one per cent

Received for publication 29 January 1979
(199) of the patients had pacemakers with a basic rate of $70 / \mathrm{min}$ and the remainder $60 / \mathrm{min}$ or less.

All electrocardiograms during permanent pacing were analysed retrospectively. Electrocardiographic recordings were made for at least 1 minute at each routine visit. Information on the indication for pacing, the stimulation rate, treatment with digitalis glycosides, and recording of intrinsic heart actvity during generator replacement was collected from the patients' records.

The electrocardiographic patterns were classed into the following 3 groups: (1) spontaneous heart activity, (2) pacemaker induced, and (3) varying heart activity, that is both spontaneous and pacemaker induced activity at either the same or subsequent follow-up visits. The appearance of ventricular ectopic beats did not influence the classification. The type of atrial activity was also noted.

A note was made of cardiac activity as seen on an oscilloscope during generator replacement with special reference to the presence of asystole during the brief period when no artificial stimulation is available. This period was not measured but it probably lasted less than 5 seconds and only on exceptional occasions was it necessary to perform external cardiac massage to maintain the circulation.

\section{Results}

The mean duration of the pacing period was 5 years (59, range 13 to 180 months). One hundred and nine patients had been paced for between 1 and 3 
years and 173 patients for more than 3 years.

Electrocardiographic findings and history of syncope before pacing are presented in Table 1; 136 patients $(48 \%)$ required pacing because of complete heart block and syncope. Complete heart block was recorded in 71 per cent of the patients before pacemaker treatment was instituted. Seconddegree atrioventricular block type 2 was recorded in $17(6 \%)$, bundle-branch block in $12(4 \%)$, and syncope of unknown cause in $6(2 \%)$. In the bundlebranch block group, 11 patients had had syncope and 1 had disabling dizziness before pacing. Five of those patients paced because of bundle-branch block had first-degree atrioventricular block combined with bifascicular bundle-branch block. In 5 of the patients in the syncopal group, an episode of asystole had been noted without any atrioventricular block being recorded. The sixth patient in this group had had first-degree atrioventricular and had had an episode of complete heart block 16 years before the present syncopal attack.

Table 1 Recorded electrocardiographic patterns before pacing and number of patients with syncope as indication for pacing

\begin{tabular}{|c|c|c|}
\hline & Number & Per cent \\
\hline Complete heart block with syncope & 136 & \multirow{2}{*}{71} \\
\hline Complete heart block without syncope & 62 & \\
\hline $\begin{array}{l}\text { Second degree atrioventricular block (type 2) } \\
\text { with syncope }\end{array}$ & 7 & \multirow[t]{2}{*}{6} \\
\hline $\begin{array}{l}\text { Second degree atrioventricular block (type 2) } \\
\text { without syncope }\end{array}$ & 10 & \\
\hline Bundle-branch block with syncope & 117 & \multirow{2}{*}{4} \\
\hline Bundle-branch block without syncope & 1 & \\
\hline Sick sinus syndrome with syncope & $35\}$ & \multirow{2}{*}{17} \\
\hline Sick sinus syndrome without syncope & 14 & \\
\hline Syncope without known cause & 6 & 2 \\
\hline Total & 282 & $100 \%$ \\
\hline
\end{tabular}

Table 2 Electrocardiographic findings during pacing in 282 patients

\begin{tabular}{|c|c|c|c|}
\hline \multirow[b]{2}{*}{ Arrhythmia before pacing } & \multicolumn{3}{|c|}{ Rhythm during pacing } \\
\hline & $\begin{array}{l}\text { Spontaneous } \\
\text { heart } \\
\text { activity }\end{array}$ & $\begin{array}{l}\text { Pacemaker } \\
\text { induced } \\
\text { rhythm }\end{array}$ & Varying \\
\hline $\begin{array}{l}\text { Complete heart block } \\
\text { Second-degree atrioventricu- }\end{array}$ & 10 & 106 & 82 \\
\hline lar block (type 2) & 5 & 8 & 4 \\
\hline Bundle-branch block & 4 & 2 & 6 \\
\hline $\begin{array}{l}\text { Sick sinus syndrome } \\
\text { Syncope without known }\end{array}$ & 9 & 2 & 38 \\
\hline cause & 5 & 一 & 1 \\
\hline Total & $33(12 \%)$ & $118(42 \%)$ & $131(46 \%)$ \\
\hline
\end{tabular}

Table 3 Asystole at generator exchange in relation to heart activity at routine controls in 232 patients

\begin{tabular}{lcc}
\hline & Asystole \\
\cline { 2 - 3 } & Number & Per cent \\
\hline Spontaneous heart activity $(n=25)$ & 0 & 0 \\
Pacemaker induced heart activity & & \\
$\begin{array}{l}\text { >3 years }(n=67) \\
\text { <3 years }(n=31)\end{array}$ & 36 & 54 \\
Varying $(n=109)$ & 6 & 19 \\
\hline Total $(n=232)$ & 19 & 17 \\
\hline
\end{tabular}

Table 2 shows the recorded rhythm during pacing in relation to the indication for pacemaker treatment. Thirty-three patients $(12 \%)$ paced because of bradyarrhythmias had spontaneous heart activity of a higher rate than that of the pulse generator at every follow-up recording. Fourteen of these had been paced for longer than 3 years. Of the 33 patients with spontaneous heart activity all through the pacing period, 10 were paced because of complete heart block. Eight of these had had Adams-Stokes attacks.

Table 3 shows the electrocardiographic pattern of the 232 patients in whom spontaneous heart activity had been recorded during generator replacement. There were no instances of asystole in patients who had had spontaneous heart activity at routine follow-up, while 42 of the 98 patients ( $43 \%$ ) with only pacemaker induced heart activity at follow-up suffered ventricular standstill. Patients treated with digitialis glycosides had asystole significantly more often as compared with the remainder: 32 per cent and 19 per cent, respectively $(P<0.05)$. These 2 groups did not differ significantly with respect to age or heart size. Among patients with complete heart block and pacemaker induced rhythm at each check-up for more than 3 years, those on digitalis had a higher incidence of asystole than those not on digitalis; 68 per cent and 38 per cent, respectively $(P<0.05)$.

Of the 233 patients paced for reasons other than the sick sinus syndrome $173(74 \%)$ had regular sinus activity at every routine follow-up visit. Of the 75 patients who were 70 years of age or younger $47(61 \%)$ showed continuous sinus activity. This group represented 20 per cent of all cases who were paced for an indication other than the sick sinus syndrome.

\section{Discussion}

Among patients with permanently implanted cardiac pacemakers because of symptomatic bradyarrhythmias, there are significant numbers who at 
routine follow-up examinations show spontaneous heart activity of a higher rate than that of their pulse generator. This finding is corroborated in our retrospective study in more than 10 per cent of our patients. Our conclusions are, however, based on recordings of heart rate and rhythm during the relatively brief routine examinations. In addition uncontrolled factors such as anxiety, inducing an increased sympathetic discharge and a subsequent increase in heart rate, may be relevant in this context in at least some patients. On the other hand, some patients with a basic pulse generator rate of $70 / \mathrm{min}$ might have had spontaneous heart activity if paced with a pulse generator with a lower basic rate.

A steady increase has occurred in permanent pacing of patients for reasons other than complete heart block and Adams-Stokes attacks since the first implantable pulse generator came into use 20 years ago (Elmqvist and Senning, 1960; Hori and Furman, 1977). In our series only 48 per cent of the patients were paced because of complete heart block and syncope as compared with 77 per cent in a series from Stockholm published 10 years ago (Edhag, 1969). This trend seems to exist in most countries where cardiac pacing is used extensively. One reason is the detection of more patients with the sick sinus syndrome which has been facilitated by the introduction of 24-hour electrocardiographic recording and of telemetry. In addition, increasing numbers of patients with bifascicular blocks with syncopal episodes are now being paced. Even if these groups are excluded there remains a high proportion of patients in our series with spontaneous heart activity at every follow-up visit. Therefore, even complete heart block of unknown cause may be paroxysmal or temporary. On the other hand, previous experience of the results of withdrawing pacemaker treatment in patients with advanced heart block with restored atrioventricular conduction who were experiencing pacemaker complications has been disappointing (Edhag, 1969).

When complete heart block occurs without obvious or treatable cause, for example, myocarditis or inferior myocardial infarction, permanent pacing for life is usually the only alternative contemplated. No case can yet be made for discontinuing permanent pacing after recording spontaneously conducted heart rhythm at follow-up visits, as the rhythms between checks are unknown. Grendahl and coworkers (1978) studied the escape rhythm in 92 patients treated with $R$ wave inhibited pacemakers because of symptomatic atrioventricular block. They found a high proportion of patients with spontaneously conducted heart activity but also a discrepancy between earlier rhythm and symptoms at pacing failure. Thus, some patients had no serious symptoms in spite of a high grade of atrioventricular block and no early escape rhythm, and others had Adams-Stokes attacks at pacing failure in spite of a constant early escape rhythm at tests. Thus, as expected, knowledge of escape rhythm at an acute investigation is not conclusive in detecting patients with permanently spontaneous heart rhythm conduction during pacing. Furthermore, sympathetic and vagal effects probably also influence escape rhythm activity.

Regular sinus activity at every routine follow-up in 60 per cent of patients less than 70 years of age and paced for reasons other than the sick sinus syndrome point to the feasibility of atrial triggered pacing in a large number of paced patients. This is of relevance as some pacemaker patients improve significantly when treated by a system that synchronises atrial and ventricular activity (Karlöf, 1975; Moss, 1975).

As repeated findings of recorded spontaneous heart activity at each visit even during long periods still cannot exclude transient conduction failure, a diagnostic pacemaker detecting episodes of extreme bradycardia or ventricular standstill has been developed (Edhag and Vallin, 1978). This combined diagnostic and therapeutic tool makes it possible to know whether the spontaneously conducting heart rhythm is stable over long periods of time. This pacer can be programmed to a conventional lithiumpowered ventricular inhibited pulse generator.

Our findings indicate that patients treated with digitalis glycosides have an increased risk of asystole during generator replacement procedures. Digitalis has been shown to have a positive inotropic effect in paced patients with cardiac failure (Benchimol et al., 1965; Donoso et al., 1965; Kaiser et al., 1965). However, a decrease in ventricular automaticity with therapeutic doses of digitalis has been found in clinical investigations (Edelist et al., 1963; Edhag and Rosén, 1969). As digitalis treatment might induce atrioventricular asynchrony resulting in worsened cardiac performance, it may be argued that diuretics alone are preferable in some paced patients.

We thank Dr Andreas Sjögren, Serafimerlasarettet, for constructive criticism of the manuscript.

This study was supported by grants from the Swedish National Association against Heart and Chest Diseases and Stockholm County Council.

\section{References}

Benchimol, A., Palmero, H. A., Liggelt, M. S., and Dimond, E. G. (1965). Influence of digitalization on the contribution 
of atrial systole to the cardiac dynamics at a fixed ventricular rate. Circulation, 32, 84-95.

Donato, L., Giuntini, C., Mariani, M., Contini, C., Barsotti, A., L'Abbate, A., and Denoth, F. (1969). Rhythm evolution during pacing with fixed rate and ventricular-synchronous pacemakers. Annals of the New York Academy of Sciences, 167, 1060-1066.

Donoso, E., Stein, W. G., Schloff, L., Cohn, L. J., and Friedberg, C. K. (1965). Effect of digitalis in compensated and decompensated patients with internal cardiac pacemakers (abstract). Circulation, 31 and 32, Suppl. II, 77.

Edelist, A., Langendorf, R., Pick, A., and Katz, L. N. (1963). Physiologic and pharmacologic studies in Stokes-Adams disease patients during the use of an artificial cardiac pacemaker. I. Effect of rapid artificial stimulation on the inherent rate of spontaneous cardiac pacemakers (abstract). Circulation, 28, 715.

Edhag, O. (1969). Long-term cardiac pacing. Experience of fixed-rate pacing with an endocardial electrode in 260 patients. Acta Medica Scandinavica, Suppl. 502, 93-96.

Edhag, O., and Rosén, A. (1969). A study on the effect of Lanatoiside C on ventricular automaticity in man. Scandinavian fournal of Clinical and Laboratory Investigation, 23, 43-47.

Edhag, O., and Vallin, H. (1978). An implantable bradycardia indicating pacer. Paper read at the First European Symposium on Cardiac Pacing in London, May 1978.

Elmqvist, R., and Senning, $\AA$. (1960). An implantable pacemaker for the heart (abstract). In Medical Electronics, pp. 253-254, ed C. N. Smyth. Iliffe London.

Grendahl, H., Miller, M., and Kjekshus, J. (1978). Overdrive suppression of implanted pacemakers in patients with AVblock. British Heart fournal, 40, 106-113.
Hori, M., and Furman, S. (1977). World survey on long-term follow-up of cardiac pacing. In Cardiac Pacing, Proceedings of the Fifth International Symposium, Tokyo 1976, pp. 577-578, ed Y. Watanabe. Excerpta Medica, Amsterdam and Oxford.

Jensen, G., Sigurd, B., Meibom, J., and Sandoe, E. (1973). Adams-Stokes syndrome caused by paroxysmal thirddegree atrioventricular block. British Heart fournal, 35, 516520.

Johansson, B. W., Karnell, J., Malm, A., Sievers, J., and Swedberg, J. (1963). Electrocardiographic studies in patients with an artificial pacemaker. British Heart fournal, 25, 514-524.

Kaiser, G. C., Willman, V. L., Cooper, T., and Hanlon, C. R. (1965). Artificial pacemakers in the treatment of heart block: importance of supplemental drug therapy (abstract). Circulation, 31 and 32, Suppl. II, 121.

Karlöf, J. (1975). Haemodynamic effect of atrial triggered versus fixed rate pacing at rest and during exercise in complete heart block. Acta Medica Scandinavica, 197, 195-206.

Moss, A. J. (1975). Therapeutic uses of permanent pervenous atrial pacemakers. A review. fournal of Electrocardiology, 8, 373-380.

Sowton, E. (1965). Artificial pacemaking and sinus rhythm. British Heart fournal, 27, 311-318.

Requests for reprints to Dr Olof Edhag, Department of Medicine, Huddinge Hospital, S-14186 Huddinge, Sweden. 